\title{
Insights into the karyotype evolution and speciation of the beetle Euchroma gigantea (Coleoptera: Buprestidae)
}

\author{
Crislaine Xavier • Rógean Vinícius Santos Soares • Igor Costa Amorim • \\ Diogo Cavalcanti Cabral-de-Mello • Rita de Cássia de Moura
}

Received: 28 December 2017 /Revised: 10 February 2018 / Accepted: 13 February 2018 /Published online: 9 March 2018

(C) Springer Science+Business Media B.V., part of Springer Nature 2018

\begin{abstract}
Euchroma Dejean, 1833 (Buprestidae: Coleoptera) is a monotypic genus comprising the species Euchroma gigantea, with populations presenting a degree of karyotypic variation/polymorphism rarely found within a single taxonomic (specific) unit, as well as drastically incompatible meiotic configurations in populations from extremes of the species range. To better understand the complex karyotypic evolution of E. gigantea, the karyotypes of specimens from five populations in Brazil were investigated using molecular cytogenetics and phylogenetic approaches. Herein, we used FISH with histone genes as well as sequencing of the COI to determine differential distribution of markers and relationships among populations. The analyses revealed new karyotypes, with variability for chromosome number and morphology of multiple sex chromosome mechanisms, occurrence of B chromosome variants (punctiform and large
\end{abstract}

Responsible Editor: Fengtang Yang

Electronic supplementary material The online version of this article (https://doi.org/10.1007/s10577-018-9576-1) contains supplementary material, which is available to authorized users.

C. Xavier · R. V. S. Soares · I. C. Amorim •

R. de Cássia de Moura $(\bowtie)$

Instituto de Ciências Biológicas, Laboratório de Biodiversidade e Genética de Insetos, Universidade de Pernambuco (UPE), Rua Arnóbio Marques 310, Santo Amaro, ZIP: 50.100-130, Recife, PE, Brazil

e-mail: ritamoura.upe@gmail.com

D. C. Cabral-de-Mello

Instituto de Biociências, Departamento de Biologia, Universidade Estadual Paulista (UNESP), Rio Claro, SP, Brazil ones), and high dispersion of histone genes in different karyotypes. These data indicate that chromosomal polymorphism in E. gigantea is greater than previously reported, and that the species can be a valuable model for cytogenetic studies. The COI phylogenetic and haplotype analyses highlighted the formation of three groups with chromosomally polymorphic individuals. Finally, we compared the different karyotypes and proposed a model for the chromosomal evolution of this species. The species E. gigantea includes at least three cytogenetically polymorphic lineages. Moreover, in each of these lineages, different chromosomal rearrangements have been fixed. Dispersion of repetitive sequences may have favored the high frequency of these rearrangements, which could be related to both adaptation of the species to different habitats and the speciation process.

Keywords Chromosomal evolution - Chromosomal rearrangement $\cdot$ Multiple sex chromosome mechanism . Molecular cytogenetics $\cdot$ Histone dispersion

$\begin{array}{ll}\text { Abbreviations } \\ \text { AL } & \text { State of Alagoas } \\ \text { COI } & \text { Cytochrome c oxidase subunit I } \\ \text { DAPI } & \begin{array}{l}\text { 2-(4-Amidinophenyl)-1H-indole-6- } \\ \text { carboxamidine }\end{array} \\ \text { DF } & \text { Federal District } \\ \text { eccDNA } & \text { Extrachromosomal circular DNA } \\ \text { FISH } & \text { Fluorescence in situ hybridization } \\ \text { PA } & \text { State of Pará } \\ \text { PE } & \text { State of Pernambuco } \\ \text { SP } & \text { State of São Paulo }\end{array}$




\section{Introduction}

Chromosomal rearrangements can promote reproductive isolation by either hybrid sterility or suppression of recombination, which are processes directly involved in speciation events (Faria and Navarro 2010). The traditional theory of chromosomal speciation, for instance, predicts that this process may occur when structural rearrangements become fixed in a population. Then, recombination among rearranged chromosomes in heterokaryotypic hybrids generates unbalanced gametes, resulting in underdominance, i.e., reduced fertility or complete sterility (Brown and O’Neill 2010). Furthermore, incompatibility between rearranged chromosomes could lead to reproductive isolation and speciation, especially when such changes are linked to the sex chromosomes (Rieseberg 2001). The role of chromosomal rearrangements in originating reproductive barriers has been investigated and reported to play an important role in isolating species or populations in some genera of Hemiptera (Mills and Cook 2014), Diptera (Noor et al. 2001; Coluzzi et al. 2002), Orthoptera (Kawakami et al. 2011), and Coleoptera (Kobayashi et al. 2000) insects.

In Coleoptera, studies on the relationship between chromosomal rearrangements and speciation are scarce. In this order, general karyotypic descriptions have been made and chromosomal rearrangements have been discussed with focus on understanding the variation in diploid number $(2 n)$ as well as the origin and evolution of sex chromosomes (Karagyan and Kuznetsova 2000; Rozek et al. 2004; Schneider et al. 2007; Cabral-deMello et al. 2008; Petitpierre 2011). However, there are few examples in which speciation processes related to chromosomal rearrangements in some genera are well documented. Among these, two general scenarios are observed in phylogenetically related or cryptic species: (i) increase or decrease in diploid number or (ii) maintenance of diploid number with change of chromosome morphology due to rearrangements or differential constitutive heterochromatin content (Kobayashi et al. 2000; Galián et al. 2007; Dutrillaux and Dutrillaux 2016).

Euchroma Dejean, 1833 (Coleoptera, Buprestidae) is a monotypic genus to E. gigantea (Linnaeus) 1758 , accounting for four subspecies with neotropical distribution: E. g. goliath, E. g. harperi, E. g. inca, and E. g. peruanum (Blackwelder 1944). Morphological variability has been observed along the species geographical distribution, whereby only the subspecies E. g. inca is recorded in Brazil (Blackwelder 1944; Bellamy 2003). From a chromosomal point of view, E. gigantea is also polymorphic among Brazilian populations from Colômbia (state of São Paulo-SP), Recife, and Igarassu (state of Pernambuco-PE). The diploid numbers $2 n=24$ or 26 have been reported in individuals from São Paulo (Mesa and Fontanetti 1984), and $2 n=32,33,34$, or 36 in individuals from Pernambuco (Moura et al. 2008). The occurrence of a multiple sex chromosome chain $\left(X_{1} Y_{1} X_{2} Y_{2} X_{3} Y_{3}\right)$ originated from sex chromosome-autosome translocations (Mesa and Fontanetti 1984; Moura et al. 2008) is noteworthy, as well as the punctiform B chromosomes varying in number from five (Moura et al. 2008) to 32 (Mesa and Fontanetti 1984). Moura et al. (2008) proposed two most likely mechanisms to explain the chromosomal variation in E. gigantea. In both cases, the sex chromosome chain was hypothesized to have emerged before the diversification of autosomal chromosomes. The first mechanism suggests that the ancestral karyotype was $2 n=36$, from which successive centric fusions resulted in reduction of the diploid number to $2 n=24$. The second hypothesis proposes that, starting from a $2 n=24$ ancestral karyotype, successive centric fissions occurred, increasing the diploid number to $2 n=36$. In addition, pericentric inversions are suggested to be responsible for changes in the proportions of chromosome arms in different karyotypes described in E. gigantea.

The chromosome features, i.e., diploid number, sex chromosomes, and the presence of B chromosomes, in E. gigantea are remarkably different from those reported for other species in the family Buprestidae, indicating the need for further investigations. In this family, the diploid number varies from $2 n=12$ in Melanophila acuminata (Buprestinae) to $2 n=46$ for Sphenoptera scovitzi (Chrysochroinae), but most species show $2 n=22$ or 20 , simple sexual mechanism, and no B chromosomes (Karagyan and Kuznetsova 2000; Karagyan et al. 2004; Karagyan and Lachowska 2007; Karagyan et al. 2012).

In this work, conventional and molecular cytogenetic analyses and phylogeny of cytochrome c oxidase subunit I (COI) were combined to unravel the complex chromosomal evolution of E. gigantea. The present data support the hypothesis of diverse chromosome rearrangements generating the high chromosomal polymorphism, as well as lineage diversification in E. gigantea. 


\section{Material and methods}

Sample collection

E. gigantea (Linnaeus, 1758) specimens were collected manually from trees of the family Malvaceae used in afforestation of urban areas in Recife (state of Pernambuco-PE), Maceió (state of Alagoas—AL), Ribeirão Preto (state of São Paulo-SP), Belém (state of Pará-PA), and Brasília (Federal District-DF), Brazil. Male individuals were predominant in all populations, and females could not be sampled in SP and PA. Sixty-two male individuals were karyotyped, 55 of which were used for molecular investigation. For COI analysis, two specimens from Colômbia (SP) were also included which were previously analyzed cytogenetically by Mesa and Fontanetti (1984) and deposited at the Zoology Museum of the University of São Paulo (MZUSP), Brazil (Fig. 1, Table 1).
Sampling was performed in accordance with Brazilian laws of environmental protection, permitted by license from IBAMA/SISBIO (No. 16278-1).

\section{Cytogenetic analyses}

Chromosomal preparations were obtained from 62 individuals by the classical method of testicular squashing, followed by conventional staining with $5 \%$ Giemsa solution. Ovaries were treated for 30 min with $0.05 \%$ colchicine solution; however, only low-quality preparations could be obtained, frequently with no metaphases. Whenever possible, the morphology of all chromosomes was also compared among individuals with the same diploid number. C-banding was performed as described by Sumner (1972), with exposure to $\mathrm{BaOH}$ (barium hydroxide) for $50 \mathrm{~s}$.
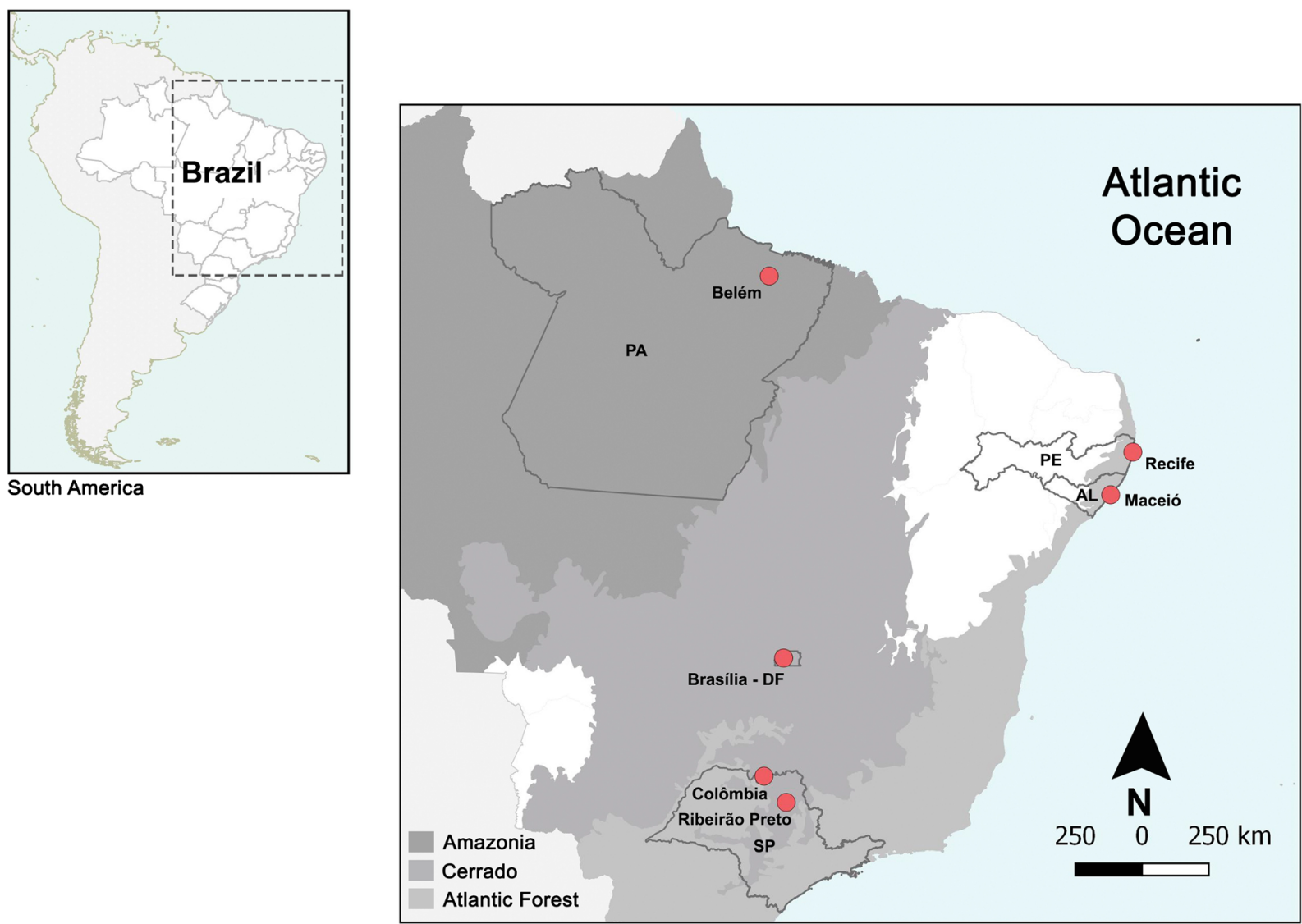

Fig. 1 Sampling sites of Euchroma gigantea used for cytogenetic and COI analyses: Pará (PA), Pernambuco (PE), Alagoas (AL), São Paulo (SP), and Federal District (DF). Coordinates: Belém-01 $28^{\prime} 13.55^{\prime \prime} \mathrm{S}, 48^{\circ} 26^{\prime} 49.98^{\prime \prime} \mathrm{W}$; Recife $-08^{\circ} 03^{\prime}$

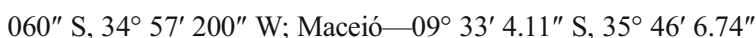
W; Ribeirão Preto-2 $1^{\circ} 10^{\prime} 16.22^{\prime \prime} \mathrm{S}, 47^{\circ} 51^{\prime} 19.67^{\prime \prime} \mathrm{W}$;

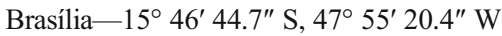


Table 1 Euchroma gigantea sampling locations, chromosomal variability, and COI Genbank accession numbers

\begin{tabular}{|c|c|c|c|c|c|}
\hline Localities & Id. sequence & GenBank accession number & $2 n$ & Sex chain & $\mathrm{B} / \mathrm{B} *$ chromosomes \\
\hline \multirow[t]{9}{*}{ Maceió, $\mathrm{AL}$} & AL1 & KY081928 & 35 & 5 & 4 \\
\hline & AL2 & KY081929 & 36 & 6 & 6 \\
\hline & AL3 & KY081930 & 36 & 6 & 4 \\
\hline & AL4 & KY081931 & 36 & 6 & 9 \\
\hline & AL5 & KY081932 & 36 & 6 & 11 \\
\hline & AL6 & KY081933 & 35 & 5 & 4 \\
\hline & AL7 & KY081934 & 35 & 5 & 14 \\
\hline & AL8 & KY081935 & 35 & 5 & 7 \\
\hline & AL9 & - & 36 & 6 & 8 \\
\hline \multirow[t]{20}{*}{ Recife, PE } & PE1 & KY081909 & 34 & 6 & 4 \\
\hline & PE2 & KY081910 & 36 & 6 & 4 \\
\hline & PE3 & KY081911 & 34 & 6 & 7 \\
\hline & PE4 & KY081912 & 36 & 6 & 5 \\
\hline & PE5 & KY081913 & 34 & 6 & 6 \\
\hline & PE6 & KY081914 & 34 & 6 & 10 \\
\hline & PE7 & KY081915 & 34 & 6 & 4 \\
\hline & PE8 & KY081916 & 34 & 6 & 8 \\
\hline & PE9 & KY081917 & 36 & 6 & 1 \\
\hline & PE10 & KY081918 & 36 & 6 & 4 \\
\hline & PE11 & KY081919 & 34 & 6 & 8 \\
\hline & PE12 & KY081920 & 34 & 6 & 14 \\
\hline & PE13 & KY081921 & 34 & 6 & 5 \\
\hline & PE14 & KY081922 & 34 & 6 & 2 \\
\hline & PE15 & KY081923 & 34 & 6 & 5 \\
\hline & PE16 & KY081924 & 34 & 6 & 5 \\
\hline & PE17 & KY081925 & 36 & 6 & 3 \\
\hline & PE18 & KY081926 & 34 & 6 & 2 \\
\hline & PE19 & KY081927 & 34 & 6 & 6 \\
\hline & PE20 & - & 34 & 6 & 2 \\
\hline \multirow[t]{10}{*}{ Belém, PA } & PA1 & KY081936 & 32 & 6 & 3 \\
\hline & PA2 & KY081937 & 32 & 6 & $4 / 2 *$ \\
\hline & $\mathrm{PA} 3$ & KY081938 & 32 & 6 & 3 \\
\hline & PA4 & KY081939 & 32 & 6 & 4 \\
\hline & PA5 & KY081940 & 32 & 6 & 4 \\
\hline & PA6 & KY081941 & 32 & 6 & 4 \\
\hline & PA7 & KY081942 & 32 & 6 & 2 \\
\hline & PA8 & KY081943 & 32 & 6 & 2 \\
\hline & PA9 & KY081944 & 32 & 6 & $5 / 1^{*}$ \\
\hline & PA10 & KY081945 & 32 & 6 & 4 \\
\hline \multirow[t]{12}{*}{ Riberão Preto, SP } & SP1 & KY081899 & 26 & 6 & 8 \\
\hline & SP2 & KY081900 & 26 & 6 & 16 \\
\hline & SP3 & KY081901 & 26 & 6 & 8 \\
\hline & SP4 & KY081902 & 26 & 6 & 12 \\
\hline & SP5 & KY081903 & 26 & 6 & 16 \\
\hline & SP6 & KY081904 & 26 & 6 & 10 \\
\hline & SP7 & KY081905 & 26 & 6 & 10 \\
\hline & SP8 & KY081906 & 26 & 6 & 16 \\
\hline & SP9 & - & 28 & 6 & 15 \\
\hline & SP10 & - & 26 & 6 & 14 \\
\hline & SP11 & - & 26 & 6 & 10 \\
\hline & SP12 & - & 26 & 6 & 10 \\
\hline
\end{tabular}


Table 1 (continued)

\begin{tabular}{|c|c|c|c|c|c|}
\hline Localities & Id. sequence & GenBank accession number & $2 n$ & Sex chain & $\mathrm{B} / \mathrm{B} *$ chromosomes \\
\hline \multirow[t]{2}{*}{ Colômbia, SP } & $\mathrm{SP} 13^{\mathrm{a}}$ & KY081907 & 24 or 26 & 5 or 6 & 16,20 or 32 \\
\hline & $\mathrm{SP} 14^{\mathrm{a}}$ & KY081908 & 24 or 26 & 5 or 6 & 16,20 or 32 \\
\hline \multirow[t]{11}{*}{ Brasília, DF } & DF1 & KY081946 & 22 & 8 & 0 \\
\hline & DF2 & KY081947 & 22 & 8 & 0 \\
\hline & DF3 & KY081948 & 22 & 6 & 0 \\
\hline & DF4 & KY081949 & 22 & 8 & 0 \\
\hline & DF5 & KY081950 & 22 & 8 & 0 \\
\hline & DF6 & KY081951 & 24 & 6 & 0 \\
\hline & DF7 & KY081952 & 22 & 8 & 0 \\
\hline & DF8 & KY081953 & 22 & 5 & 0 \\
\hline & DF9 & KY081954 & 22 & 6 & 0 \\
\hline & DF10 & KY081955 & 22 & 6 & 0 \\
\hline & DF11 & - & 22 & 6 & 0 \\
\hline
\end{tabular}

$B$, punctiform B chromosomes; $B^{*}$, large $\mathrm{B}$ chromosomes

${ }^{\mathrm{a}}$ Two individuals analyzed by Mesa and Fontanetti (1984)

Fluorescence in situ hybridization (FISH) was performed as described by Pinkel et al. (1986) with modifications (Cabral-de-Mello et al. 2010). Genomic DNA was extracted from leg muscle tissue using the phenolchloroform procedure described by Sambrook and Russel (2001). H3 and H4 histone gene sequences were obtained from the genome of E. gigantea using specific primers described by Cabral-de-Mello et al. (2010) and Pineau et al. (2005), respectively. PCR products were sequenced by Macrogen Inc. (Korea), and the sequences were deposited in GenBank (accession numbers: KX885406, KX885407). The reactions were performed in a volume of $50 \mu \mathrm{L}$ containing $1 \mathrm{X} \mathrm{Taq}$ DNA polymerase recombinant buffer (Invitrogen), $1.5 \mathrm{mM}$ of $\mathrm{MgCl}_{2}, 0.02 \mathrm{mM}$ of dNTP, $0.4 \mu \mathrm{M}$ of each primer and 0.02 units of Taq DNA polymerase. The PCR program consisted of initial denaturation for $5 \mathrm{~min}$ at $94^{\circ} \mathrm{C} ; 30$ cycles of $1 \mathrm{~min}$ at $94{ }^{\circ} \mathrm{C}$; $30 \mathrm{~s}$ at $55^{\circ} \mathrm{C} ; 60 \mathrm{~s}$ at $72{ }^{\circ} \mathrm{C}$; and final extension for $5 \mathrm{~min}$ at $72{ }^{\circ} \mathrm{C}$. The $\mathrm{H} 3$ and $\mathrm{H} 4$ histone probes were labeled by nick translation using digoxigenin-dUTP (Roche) and biotin-14-dATP (Invitrogen, San Diego, CA, USA), following the guidelines of the suppliers. The H3 histone probe was detected with anti-digoxigenin-rhodamine (Roche), and the $\mathrm{H} 4$ histone probe was detected with avidin-FITC (fluorescein isothiocyanate) (Invitrogen, San Diego, CA, USA). Whenever possible, two probes were combined in the same slide.

The cells were analyzed in an Olympus microscope BX61 equipped with a fluorescent lamp. The images were captured using a DP70 cooled digital camera, and the brightness and contrast of photographs were optimized using the software Photoshop CC 2014.

Phylogenetic analysis

A fragment of cytochrome c oxidase subunit I (COI) gene from 53 karyotyped individuals plus the two specimens provided by MZUSP was amplified using the primers C1-J-2183 (Jerry) - 5' CAA CAT TTA TTT TGA TTT TTT GG - and TL2-N-3014 (Pat) - 5' TCC AAT GCA CTA ATC TGC CAT ATT A (Simon et al. 1994). The reactions were performed in a volume of $50 \mu \mathrm{L}$ containing $1 \mathrm{X} \mathrm{Taq}$ DNA polymerase recombinant buffer (Invitrogen), $1.5 \mathrm{mM}$ of $\mathrm{MgCl}_{2}, 0.02 \mathrm{mM}$ of dNTP, $0.4 \mu \mathrm{M}$ of each primer, and $0.02 \mathrm{U}$ of Taq DNA polymerase. The PCR program was conducted as follows: initial denaturation for 5 min at $94{ }^{\circ} \mathrm{C} ; 40$ cycles of $30 \mathrm{~s}$ at $94{ }^{\circ} \mathrm{C} ; 30 \mathrm{~s}$ at $55^{\circ} \mathrm{C} ; 1 \mathrm{~min}$ at $72{ }^{\circ} \mathrm{C}$; and final extension for $5 \mathrm{~min}$ at $72{ }^{\circ} \mathrm{C}$. The PCR products were purified using the ExoSAP-IT (Affymetrix) reagent, following the guidelines of the suppliers, and sequenced with the Jerry primer by Macrogen Inc. (Korea).

Chromatograms were analyzed using the Pregap4 software, Staden package (Bonfield et al. 1995). The sequences were aligned with the program Clustal W (Thompson et al. 1994) and genetic distances were calculated using Kimura's two-parameter model (Kimura 1980), both implemented in the MEGA 6 software (Tamura et al. 2013). A phylogenetic analysis using Bayesian inference was performed with the program 
MrBayes 3.2.2 (Ronquist et al. 2012), and the appropriate model of nucleotide sequence evolution determined using jModelTest (http://jmodeltest.org) was applied (HKY + G). Two independent replicates of the Markov chain Monte Carlo search were performed with 10,000,000 simulations, each with eight chains. Trees were sampled every 100 generations, and the first $25 \%$ were discarded as "burn-in". The analysis was ran in the CIPRES Science Gateway (Miller et al. 2010). Maximum likelihood analysis was performed using raxmlGUI 1.2 (Silvestro and Michalak 2011) with 1000 bootstrap replications. Homologous sequences of Embrikillium patricium (KM364387 ), Buprestis laeviventris (KM364353), Sphenoptera sp. (KM364392), and Selagis caloptera (KM364373) (Buprestidae) were used as out-group. The topological relationship between the haplotypes was estimated using the program Network 5.0 (http://www.fluxuxengineering.com) with the median-joining approach.

\section{Results}

\section{Karyotypes}

Extensive intra- and interpopulation chromosomal variability was observed in meiotic and mitotic cells of the 62 studied individuals (Fig. 2, Figs. S1-S11). Diploid numbers ranged from $2 n=22$ to $2 n=36$. Variation in chromosome number was found in Brasília, DF ( $2 n=22$ and 24), Maceió, AL ( $2 n=35$ and 36), Recife, PE ( $2 n=34$ and 36), and Ribeirão Preto, SP ( $2 n=26$ and 28), whereas a single karyotype with $2 n=32$ was found in Belém, PA (Table 1, Fig. 2, Figs. S1-S11). All these karyotypes harbor multiple sex chromosome chains consisting of five $\left(\mathrm{X}_{1} \mathrm{Y}_{1} \mathrm{X}_{2} \mathrm{Y}_{2} \mathrm{X}_{3}\right)$, six $\left(X_{1} Y_{1} X_{2} Y_{2} X_{3} Y_{3}\right)$, or eight $\left(X_{1} Y_{1} X_{2} Y_{2} X_{3} Y_{3} X_{4} Y_{4}\right)$ chromosomes, which were observed in five, 52, and five individuals, respectively. Individuals bearing the chain with six chromosomes were observed in all populations, and that from Maceió, AL, further presented specimens with five chromosomes in sex chromosome chain. Brasília, DF, was the most diverse population, exhibiting the three aforementioned multivalent sex chain compositions. Moreover, we found punctiform B chromosomes in 51 individuals, except in those from Brasília, DF (Table 1, Fig. 2), and a large type of B chromosome in two individuals from Belém, PA (Table 1, Fig. 2).

Karyotypes with $2 n=22$ were polymorphic for autosomal morphology and number of chromosomes in sex chain, which comprised five, six, or eight chromosomes
(Fig. 2a-c). One individual presented five sex chromosomes, as well as four meta-submetacentric and two acrocentric pairs, one heteromorphic pair composed of one submetacentric and one acrocentric chromosome, and a trivalent formed by one metacentric and two acrocentric chromosomes (Fig. 2a, Fig. S1), resulting in gametes with ten or 12 chromosomes (Fig. S1). Individuals with six sex chromosomes presented seven biarmed autosomal and one acrocentric pair (Fig. 2b, Fig. S2). Finally, in individuals showing $2 n=22$ with eight sex chromosomes, we observed five biarmed and two acrocentric bivalents (Fig. 2c, Fig. S3). Only one specimen presented $2 n=24$, showing six sex chromosomes and one submetacentric, five metacentric and three acrocentric autosomal pairs (Fig. 2d, Fig. S4). The karyotype with $2 n=26$ showed five metacentric and five acrocentric autosomal pairs, and $2 n=28$ displayed four metacentric and seven acrocentric autosomal pairs; both karyotypes harbored sex chains composed of six chromosomes (Fig. 2e, f, Figs. S5 and S6). $\mathrm{B}$ chromosomes with number ranging from eight to 16 in $2 n=26$ and $2 n=28$ individuals were noticed (Table 1).

Individuals with $2 n=32$ were found in Belém, PA. They presented one or two submetacentric pairs and the remaining autosomal pairs with acrocentric morphology, and sex chromosome chain with six chromosomes (Fig. 2 g, Figs. S7 and S8). These specimens exhibited two to five punctiform B chromosomes, and two individuals showed large meta-submetacentric B chromosomes (Table 1, Fig. 2g, Fig. S8).

Specimens with $2 n=34$ were found in Recife, PE, showing one metacentric and 13 acrocentric autosomal pairs (Fig. 2h, Fig. S9), in addition to B chromosomes ranging in number from two to 14 (Table 1). In individuals with $2 n=35$, polymorphisms in autosomal morphology were observed: either all autosome pairs were acrocentric or only the major autosome pair was submetacentric, which was also observed in heteromorphic condition. All these individuals presented a sex chromosome chain formed by five chromosomes (Fig. 2i, Fig. S10) and B chromosomes with number varying from four to 14 (Table 1). Individuals with $2 n=36$ were found in Maceió, AL, and Recife, PE. However, despite maintenance of diploid number, sex chromosome chain with six chromosomes and most autosomes being acrocentric, polymorphisms in the major autosome pair were detected in both localities, showing acrocentric or submetacentric morphology, or heteromorphic condition 


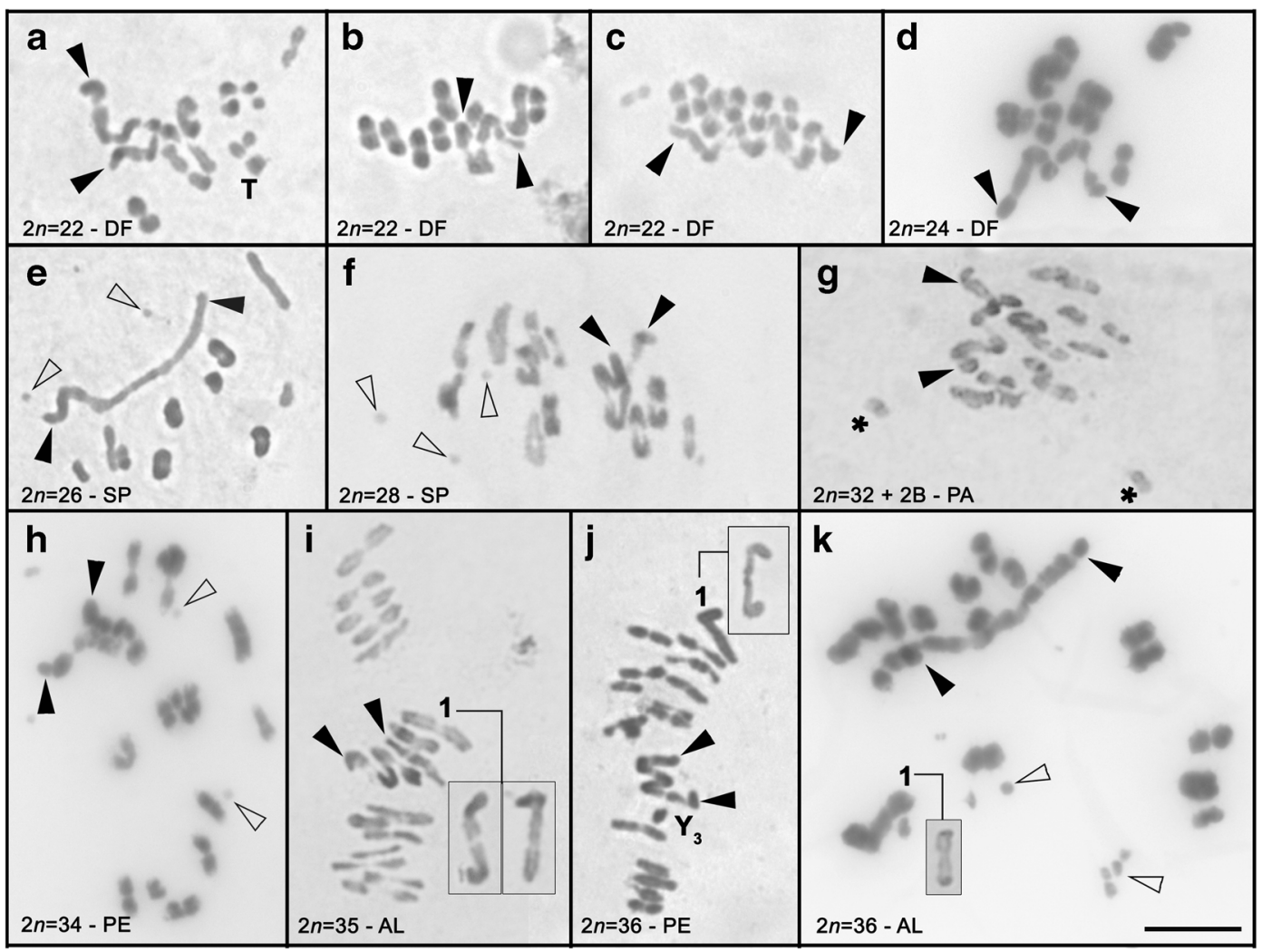

Fig. 2 Chromosomal variation in metaphase I of Euchroma gigantea from (a-d) Brasília, DF; (e, f) Ribeirão Preto, SP; (g) Belém, PA; (h, j) Recife, PE; and (i, k) Maceió, AL. Black arrowheads indicate the ends of the sex chromosome chains with (a, i) five, $(\mathbf{b}, \mathbf{d}-\mathbf{h}, \mathbf{k})$ six, or (c) eight chromosomes. Note the

(Fig. 2j, k, Fig. S11). Punctiform B chromosomes varied in number from one to 14 (Table 1).

Regarding the sex chromosome chain, differences in chromosomal morphology were observed even when the number of chromosomes is the same (Figs. 3 and 6, Figs. S1-S11). It was not possible to determine the proto $\mathrm{X}$ or proto $\mathrm{Y}$ chromosome, nor the homologies among all chromosomes in different chain configurations. However, the $\mathrm{X}_{1}$, identified through morphology by Mesa and Fontanetti (1984) and Moura et al. (2008), is similar in all karyotypes. Hence, starting the sex chromosome chain from $\mathrm{X}_{1}$, the other chromosomes could be denominated. In specimens from Brasília, $\mathrm{DF}$, the chain with $\mathrm{X}_{1} \mathrm{Y}_{1} \mathrm{X}_{2} \mathrm{Y}_{2} \mathrm{X}_{3}$ was composed only of biarmed chromosomes (Fig. 3a-c). In the sex chromosome chain with $\mathrm{X}_{1} \mathrm{Y}_{1} \mathrm{X}_{2} \mathrm{Y}_{2} \mathrm{X}_{3} \mathrm{Y}_{3}, \mathrm{X}_{2}$ had acrocentric morphology while the other chromosomes were biarmed (Fig. 3d-f). Finally, in the specimens from Brasília, DF, with $\mathrm{X}_{1} \mathrm{Y}_{1} \mathrm{X}_{2} \mathrm{Y}_{2} \mathrm{X}_{3} \mathrm{Y}_{3} \mathrm{X}_{4} \mathrm{Y}_{4}, \mathrm{X}_{2}$ and $\mathrm{X}_{4}$ presence of an autosomal trivalent (T) in a. Hollow arrowheads indicate examples of punctiform B chromosomes $(\mathbf{e}, \mathbf{f}, \mathbf{g}, \mathbf{k})$. Note two large B chromosomes $(*)$ in $\mathbf{g}$. Insets in $\mathbf{i}-\mathbf{k}$ represent the alternative conditions of pair 1 in these karyotypes. $B a r=10 \mu \mathrm{m}$

were acrocentric and the other chromosomes were biarmed (Fig. 3g-i).

In all analyzed specimens from Ribeirão Preto, SP, Belém, PA, and Recife, PE, and four individuals from Maceió, AL, the sex chromosome chain contained six chromosomes and showed similar chromosome morphology. While all $\mathrm{X}$ chromosomes in addition to $Y_{1}$ and $Y_{2}$ showed metasubmetacentric morphology, $\mathrm{Y}_{3}$ was acrocentric (Fig. 3j-1). Further, $Y_{3}$ was absent in four specimens from Maceió, AL (Figs. $2 \mathrm{i}$ and $3 \mathrm{p}-\mathrm{r}$ ).

Very weak $\mathrm{C}$ bands were observed in the pericentromeric region of autosomal chromosomes in individuals with $2 n=35, \mathrm{X}_{1} \mathrm{Y}_{1} \mathrm{X}_{2} \mathrm{Y}_{2} \mathrm{X}_{3}$ from Maceió, $\mathrm{AL}$, with the exception of the heteromorphic pair 1, where the short arm of the submetacentric chromosome was entirely heterochromatic. In addition, intense bands were present in the pericentromeric region of sex chromosomes (Fig. S12). 

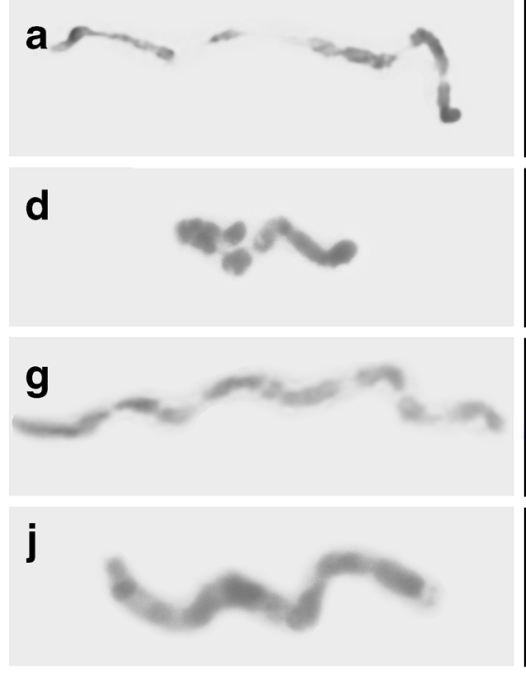

m

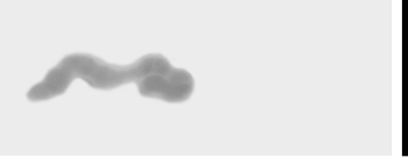

p

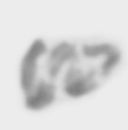

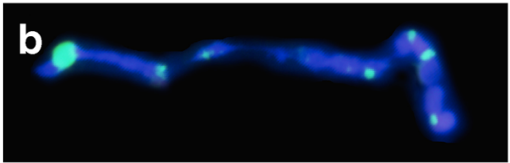
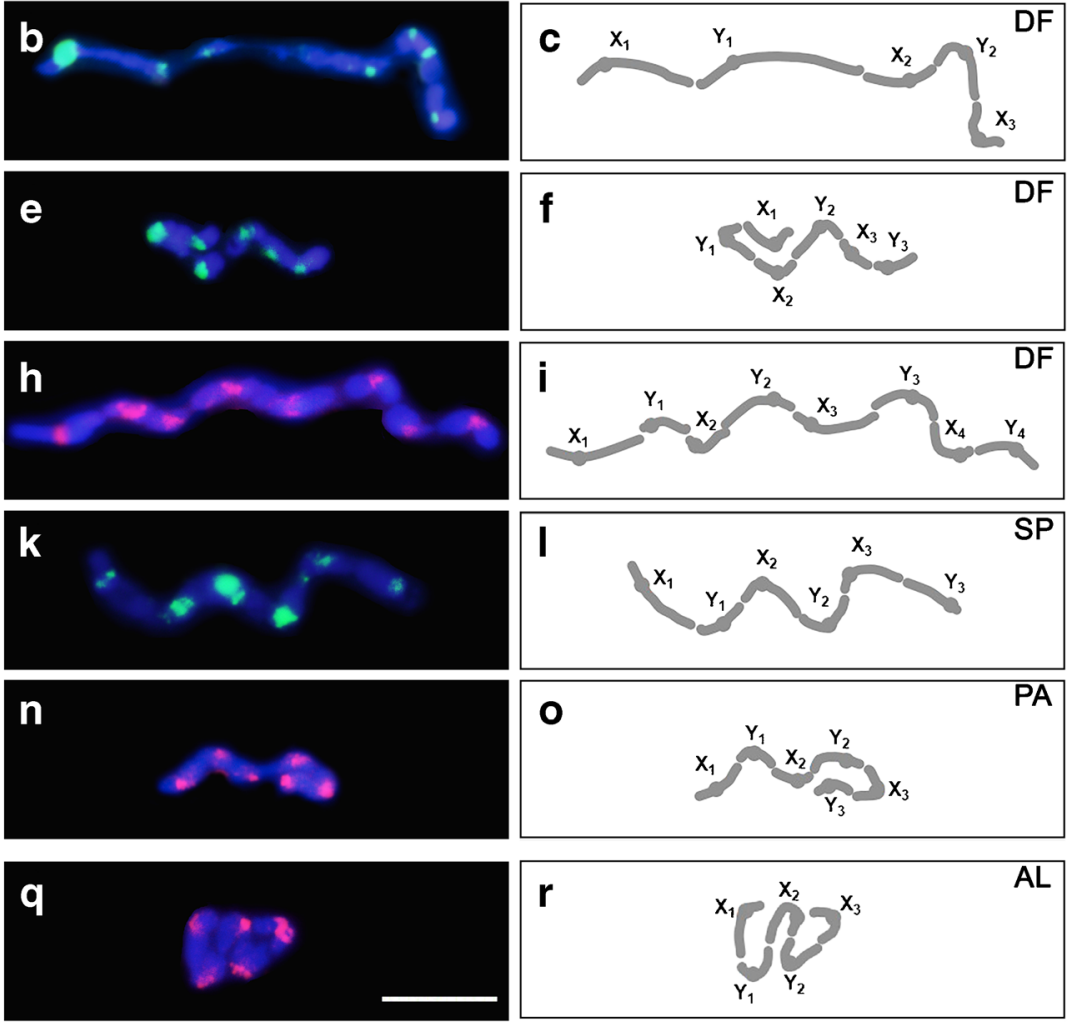

Fig. 3 Variability of multiple sex chromosome mechanism in Euchroma gigantea. Conventional (a, p) and inverted DAPI staining $(\mathbf{d}, \mathbf{g}, \mathbf{j}, \mathbf{m})$. The same chain is shown in the second column,

Phylogeny of COI and haplotype network

The COI sequences had an average length of $751 \mathrm{bp}, 50$ of which were variable sites, resulting in 22 haplotypes. The Bayesian and maximum likelihood phylogenetic analysis showed a similar topology. They revealed a monophyletic group, and three main clades were highlighted (Fig. 4a). Three haplogroups were retrieved by the median-joining haplotype network (Fig. 4b). Samples from the same locality were grouped regardless of diploid or sex chromosome number. Groupings coincided with the Brazilian geographical regions Northeast and North, and individuals from the Southeast and Midwest were clustered into the same clade/group. The pairwise distance of $\mathrm{COI}$ within each of these groups ranged from 0 to $4 \%$, and from 2 to $7 \%$ between groups (Table 2).

\section{Chromosomal location of histone genes}

The FISH technique using $\mathrm{H} 3$ and $\mathrm{H} 4$ histone genes as probes was performed in at least one representative of after FISH with histone $\mathrm{H} 4$ (green) or H3 (red) as probe, and respective drawing schemes are shown in the third column. Bar $=$ $10 \mu \mathrm{m}$

each collection site, and multiple sites were noticed. All signals were co-located in pericentromeric regions of all autosome and sex chromosomes (Figs. 3 and 5, Fig. $\mathrm{S} 13)$. As these sequences were located in pericentromeric regions of all chromosomes, they helped define autosomal polymorphisms with regard to morphology.

\section{Discussion}

The high incidence of chromosomal polymorphism in Euchroma gigantea

The description of new karyotypes with $2 n=22,2 n=$ 28 , and $2 n=35$ and the uncovering of morphological variation in karyotypes with the same diploid number and in sex chromosomes provided in this work expand the current view on chromosomal variability in E. gigantea. Our results depict a wider karyotypic variation than previously described by Mesa and Fontanetti (1984) and Moura et al. (2008), and suggest 


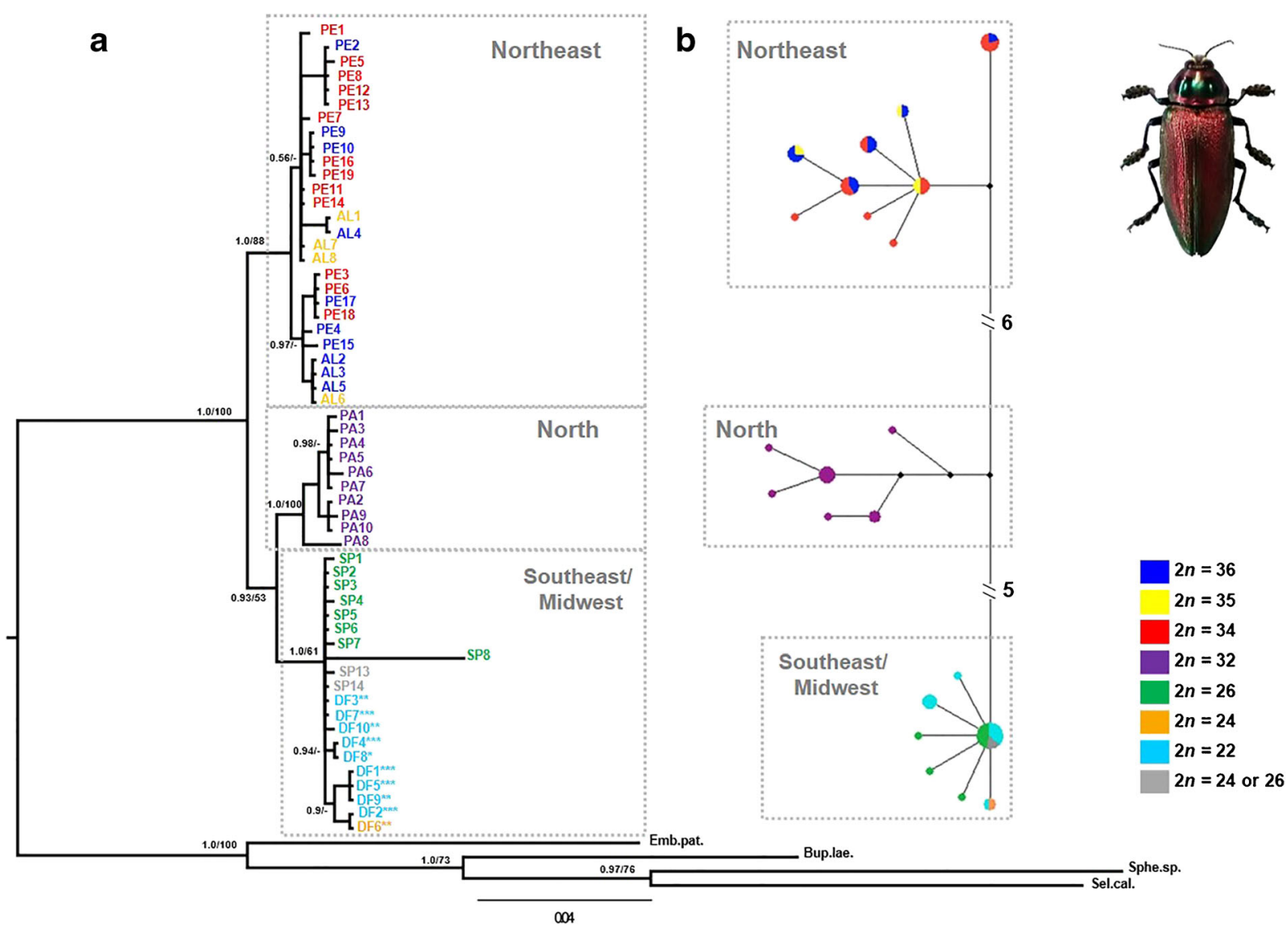

Fig. 4 (a) Bayesian phylogenetic tree and (b) median-joining haplotype network topology for COI fragment from Euchroma gigantea. Abbreviations of sampling sites are shown in the tree and correspond to those in Table 1. The posterior probabilities/ maximum likelihood bootstrap values are given near the branches. The scale bar indicates 0.04 change per site. In the network topology, small black circles represent extinct or unsampled

that intense chromosomal evolution in the species might have resulted diversification of cryptic species in the genus. Considerable level of karyotypic diversity has been described in other Coleoptera genera. For instance, in the genus Blaps (Tenebrionidae), species are found haplotypes; numbers next to the network correspond to the number of steps among the lineages; and circle areas are proportional to the haplotype frequencies. Emb. pat.: Embrikillium patricium, Bup. lae. Buprestis laeviventris, Sphe. sp. Sphenoptera sp., and Sel. cal.: Selagis caloptera. Asterisks (*) next to the specimen abbreviation in DF samples correspond to the sexual chain with five $(*)$, six $(* *)$, or eight $(* * *)$ chromosomes

displaying $2 n=19,21,34,35,36,37$, or 38 and may have multiple sex chromosome systems varying from XXY to $\mathrm{X}_{1-12} \mathrm{Y}_{1-6}$ (Juan and Petitpierre 1991; Vitturi et al. 1996). In the suborder Polyphaga, centric fissions and fusions, in addition to translocations and loss of Y,

Table 2 Pairwise distance of cytochrome oxidase c I subunit within and between populations of Euchroma gigantea. The means (minimum-maximum) of pairwise distances are indicated

\begin{tabular}{llll}
\hline & Within populations & \multicolumn{2}{l}{ Between populations } \\
\cline { 4 - 4 } & & Northeast & North \\
\hline Northeast & $0.01(0-0.01)$ & & $0.03(0.03-0.04)$ \\
North & $0.00(0-0.01)$ & $0.03(0.02-0.07)$ & $0.03(0.02-0.06)$ \\
Southeast/Midwest & $0.01(0-0.04)$ & & \\
\hline
\end{tabular}



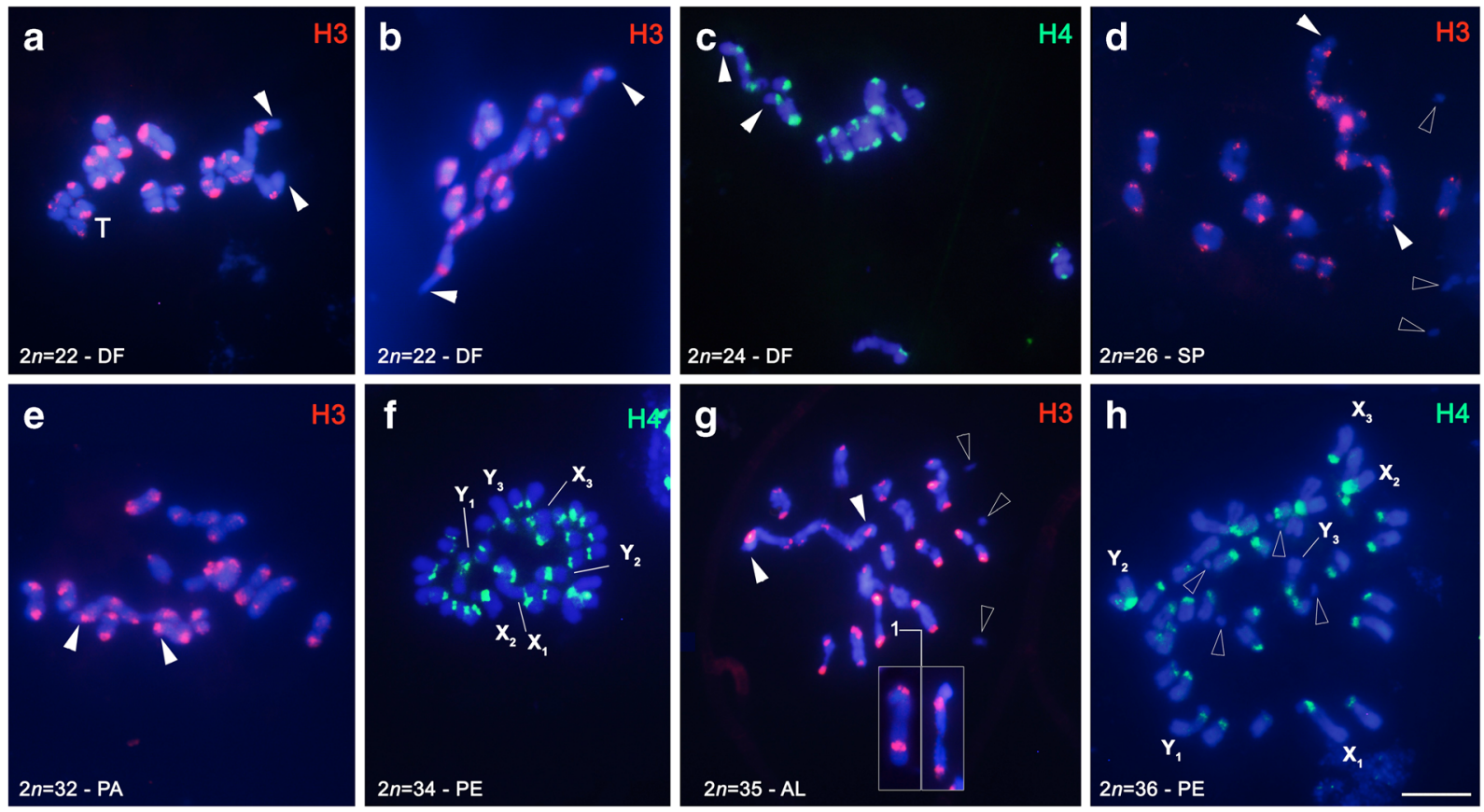

Fig. 5 FISH mapping of histones $\mathrm{H} 3$ and $\mathrm{H} 4$ in $(\mathbf{a}-\mathbf{e}, \mathbf{g})$ meiotic and (f, h) mitotic cells of Euchroma gigantea. White arrowheads indicate the ends of the sex chromosome chains with $(\mathbf{a}, \mathbf{g})$ five, $(\mathbf{c}$,

have generated polymorphisms in some species. For instance, Botanochara bonariensis (Chrysomelidae) presents $2 n=27$, Хyy; 41, Хуy; 44, XXXY; and 47, XXY (De Julio et al. 2010); whereas Anthonomus bisignifer (Curculionidae) shows $2 n=19, \mathrm{XO} ; 30$, $\mathrm{Xy}_{\mathrm{p}} ; 32, \mathrm{Xy}_{\mathrm{p}} ; 34, \mathrm{Xy}_{\mathrm{p}}$; and $36, \mathrm{Xy}_{\mathrm{p}}$ (Blackmon and Demuth 2015). However, polymorphisms at species level observed in other Coleoptera or even Buprestidae (Karagyan and Kuznetsova 2000; Karagyan et al. 2004; Karagyan and Lachowska 2007; Karagyan et al. 2012) are smaller than the karyotypic polymorphism observed in E. gigantea.

Comparison among the E. gigantea karyotypes evidenced the occurrence of autosome-autosome and autosome-sex chromosome translocations, fissions, fusions, pericentric inversions, and $\mathrm{Y}_{3}$ loss in the chromosomal evolution of this species. These rearrangements are also observed in the karyotype evolution of other Coleoptera (Cabral-de-Mello et al. 2008; De Julio et al. 2010). Besides these rearrangements, comparison of the pair 1 in $2 n=35$ individuals suggests amplification or loss of heterochromatin, as the short arm of the submetacentric chromosome was entirely heterochromatic whereas the size of the acrocentric counterpart corresponded to the long arm of the submetacentric one (Figs. 2i, Fig. S12). d, e) six, or (b) eight chromosomes. Insets in (g) represent the alternative conditions to pair 1 in this karyotype. Bar $=10 \mu \mathrm{m}$

This suggests that heterochromatin amplification or loss could be responsible for morphology variation among individuals for pair 1. Based on the distribution of E. gigantea karyotypes in Brazilian populations and the COI phylogeny that showed an evident separation of individuals below and above $2 n=30$, we proposed an evolutionary scenario for the chromosomal diversification of this species (Fig. 6), described in detail below.

From the putative karyotype with $2 n=20$, Xy, which is ancestral for Coleoptera and also described for Buprestidae (Karagyan and Kuznetsova 2000; Karagyan et al. 2004; Karagyan et al. 2012), one autosome fission originated $2 n=22$, which is the modal karyotype in this family (Karagyan and Kuznetsova 2000). The occurrence of a multiple sexual chain with six chromosomes in all analyzed populations and in a large number of individuals (55 out of 62) suggests that it was likely present in the ancestor of E. gigantea, as previously proposed by Mesa and Fontanetti (1984), and originated before other chromosomal reorganizations, such as increasing diploid numbers. Therefore, we propose that sex chromosome-autosome translocations originated a chromosome chain with six sex chromosomes $\left(\mathrm{X}_{1} \mathrm{Y}_{1} \mathrm{X}_{2} \mathrm{Y}_{2} \mathrm{X}_{3} \mathrm{Y}_{3}\right)$ from the karyotype with $2 n=22$, Xy. Subsequently, the occurrence of additional 
a

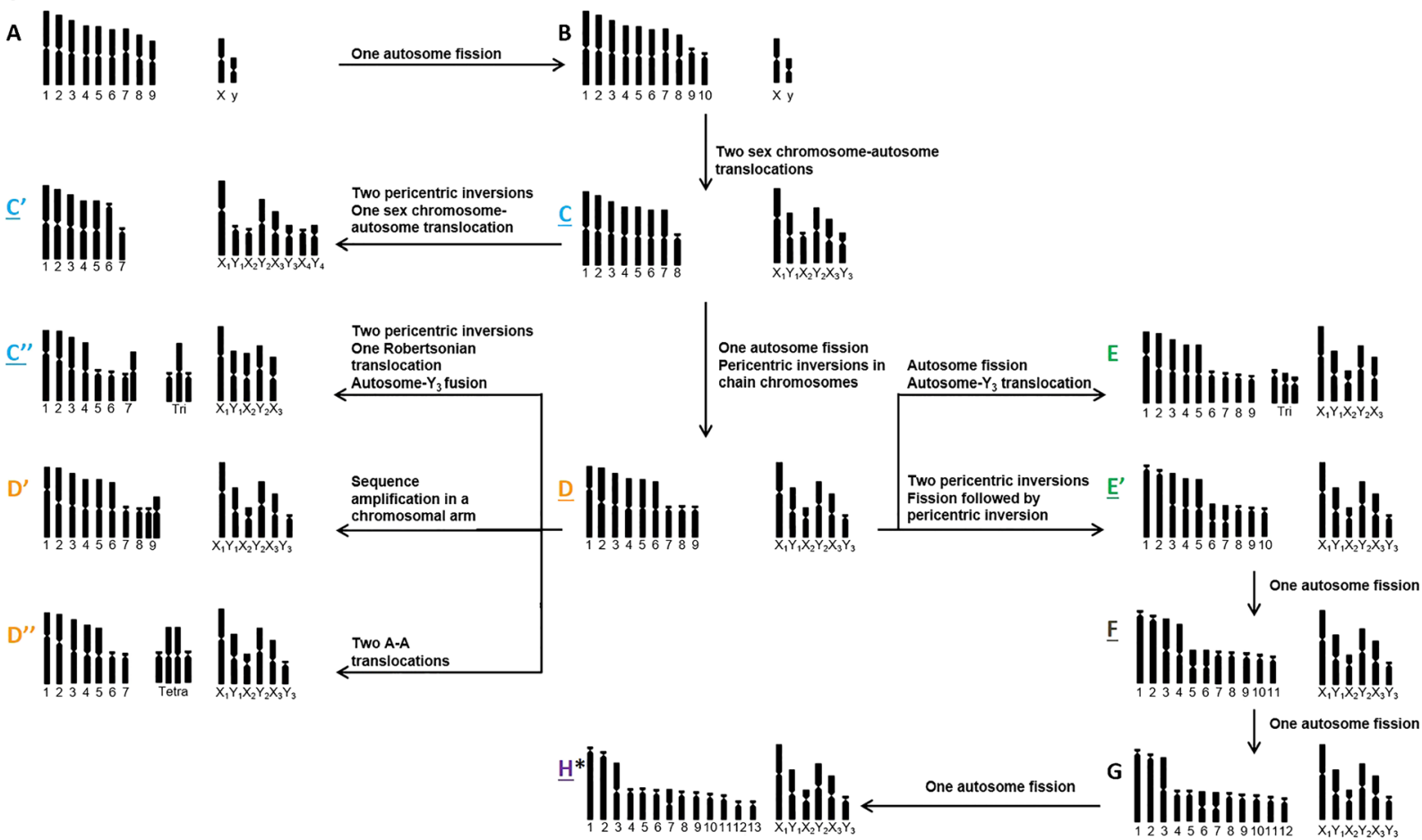

\section{b}
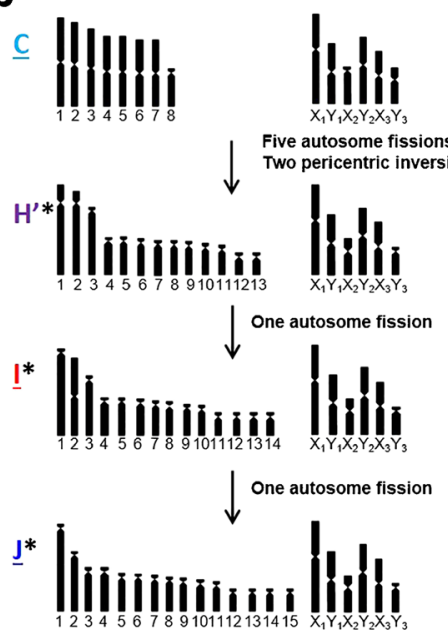

Hypothetical to Euchroma

$2 n=22$

$2 n=24$

$2 n=26$

Fig. 6 Hypotheses of chromosomal evolution in Euchroma gigantea (a, b). Idiograms A and B (a) correspond to Coleoptera and Buprestidae modal karyotypes, respectively. Underlined letters are karyotypes described in this work; remaining

autosome-sex chromosome translocation increased the number of chromosomes in the chain. Starting from a $2 n=22, X_{1} Y_{1} X_{2} Y_{2} X_{3} Y_{3}$ state, one autosome fission

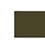

karyotypes were described in Mesa and Fontanetti (1984) and Moura et al. (2008). *Pericentric inversions were observed in one or two pairs of these karyotypes

originated a karyotype with $2 n=24$ (Fig. 6a) and, from it, pericentric inversions, a Robertsonian translocation and $\mathrm{Y}_{3}$-autosome fusion originated the 
karyotype with $2 n=22, \mathrm{X}_{1} \mathrm{Y}_{1} \mathrm{X}_{2} \mathrm{Y}_{2} \mathrm{X}_{3}$, which has an autosomal trivalent and one heteromorphic pair. From the karyotype with $2 n=24$, fission events, pericentric inversions, and autosome-autosome (A-A) translocations caused an increase of diploid number to $2 n=32$, change of chromosomal morphology, and originated tri- or tetravalents in individuals from the Southeast/ Midwest and North clades (Fig. 6a).

Karyotypes found in the Northeastern population may have arisen from that with $2 n=32$ found in the Northern group through autosome fission and pericentric inversions (Fig. 6a). Nevertheless, the karyotype with $2 n=32$ from Pernambuco described by Moura et al. (2008) may have originated independently, through centric fissions and pericentric inversions, from $2 n=22$ with six sex chromosomes (Fig. 6b). From this $2 n=32$ set, karyotypes with $2 n=34$ and 36 probably originated through centric fissions (Fig. 6b). As suggested for other organisms, the high number of chromosomal rearrangements throughout the karyotype evolution of E. gigantea may have favored the emergence of punctiform B chromosomes (Colombo and Remis 1997; Rosetti et al. 2007; Martis et al. 2012; Zhou et al. 2012; Houben et al. 2014). The occurrence of B chromosome variants (punctiform and large ones) in distinct populations suggests multiple B chromosome origins or different evolution, further supporting the extensive chromosomal variability of the species. The absence of B chromosomes in the population from Brasília, DF, and the presence of large B chromosomes exclusively in individuals from Belém, PA, indicate that different factors may be acting on the maintenance and dynamics of these chromosomes in E. gigantea. Such factors may be mechanisms of origin, composition of these chromosomes, and the possible selective pressure which individuals are subject to in accordance with different environmental conditions (Camacho 2005).

Meiotic chains as observed in E. gigantea are also found in other animals, such as the huntsman spider Delena cancerides (Rowell 1990; Sharp and Rowell 2007), the centipede Otocryptops sexspinosus (White 1973), the termite Incisitermes schwarzi (Syren and Luykx 1977), the platypus Ornithorhynchus anatinus (Rens et al. 2004), and many tiger beetles (Cicindelidae) (Galián et al. 2007). In some species, the number of chromosomes involved in the chain is conserved between individuals (Rens et al. 2004). However, polymorphisms can be found and might indicate either recent or rapid evolution of the chain, especially when there is no genetic differentiation among individuals with distinct karyotypic features (Luykx and Syren 1981; Rowell 1990). Meiotic chain polymorphisms are not often tolerated in many species, as they can disrupt the correct segregation of chromosomes and, thus, the essential formation of balanced gametes. The segregation of contiguous elements can lead to migration of two chromosomes with partial homology to the same pole, resulting in aneuploid gametes (Gruetzner et al. 2006; Sharp and Rowell 2007). The alternate orientation of chromosomes $X$ and $\mathrm{Y}$ at the first meiosis in the chains, seen in E. gigantea (Fig. 2, Figs. S1-S11), may have favored correct segregation and consequent production of balanced gametes.

The sex chromosome chains composed of five elements found in Brasília, DF, and Maceió, AL, probably have independent origins. While the individual with $2 n=$ 22 presents a heteromorphic pair that probably contains $\mathrm{Y}_{3}$ chromosomes, individuals with $2 n=35$ seem to have lost the $\mathrm{Y}_{3}$ chromosome. Loss of the $\mathrm{Y}$ chromosome has been reported in many groups of Coleoptera, including the suborders Adephaga and Polyphaga (Schneider et al. 2007; Cabral-de-Mello et al. 2008; De Julio et al. 2010). One hypothesis for this evolutionary event is that the $\mathrm{Y}$ chromosome could accumulate transposable elements, especially retrotransposons, which can change the chromatin structure from a euchromatic nature into a heterochromatic one, and thus contribute to $\mathrm{Y}$ degeneration with consequent loss (Steinemann and Steinemann 1998). On the other hand, in multiple sex systems, the loss of Y was reported in the monotreme echidna Tachyglossus aculeatus. In this species, inversion in the Y chromosome might suppress the meiotic synapsis and chromosome recombination, contributing to its differentiation, degradation, and ultimately entire loss (Gruetzner et al. 2006).

The presence of individuals with heteromorphic pairs in the Northeast clade and of polymorphic karyotypes $2 n=22$ in the Southeast/Midwest clade indicate the possibility of crossing between parental specimens with the same diploid number, but cytogenetically distinct. However, the only available study regarding E. gigantea viability, performed in natural population of the city of Goiânia (state of Goiás, GO), has revealed that part of the offspring was inviable, namely, the survival of larvae, pre-pupal and pupal stages declined by 72, 63, and $69 \%$, respectively (Garcia 1998). Karyotypes of individuals from Goiânia were not known, but possibly presented polymorphisms as seen in other populations 
of the Southeast/Midwest clade in which they were included (data not shown). Thus, the observed viability decline (Garcia 1998) could be related to fertilization of unbalanced gametes.

Our genetic variation data for in E. gigantea support the existence of at least three lineages and suggest that chromosomal divergence could be involved in the speciation process, as seen in other insect species (Coluzzi et al. 2002; Mills and Cook 2014). In addition, the three lineages of E. gigantea were formed by individuals belonging to distinct biomes that possess different physical, climatic, geographic, and lithological conditions, with specific fauna and flora (Coutinho 2006). Hence, differential fixation of rearrangements, such as translocations, fissions, or inversions, among E. gigantea populations may involve adaptive processes, as reported for several eukaryotes (Coghlan et al. 2005; Crombach and Hogeweg 2007; Taffarel et al. 2015), whereby rearrangements can be correlated with phenotypic differences that confer varying fitness in different habitats (Coghlan et al. 2005).

Histone genes were amplified in centromeres of Euchroma gigantea

The co-localization of $\mathrm{H} 3$ and $\mathrm{H} 4$ histone genes observed in E. gigantea chromosomes was expected. In Coleoptera, as well as in other insects, these genes are usually found near H1, H2A, and H2B genes, in a quintet array repeated in tandem (Nagoda et al. 2005; Roehrdanz et al. 2010). However, the dispersion of histone sequences in all chromosomes was surprising. Most of the 15 Coleoptera species mapped for histone genes presented two FISH signals exclusively in autosome pairs (Cabral-de-Mello et al. 2011; Goll et al. 2015). Three exceptions were Scarabaeidae species that showed one or two sites located in sex chromosomes, or six sites in autosomes and the $\mathrm{X}$ chromosome (Cabral-de-Mello et al. 2011). Dispersion of histone sequences was also observed in grasshoppers (Oliveira et al. 2011; Bueno et al. 2013). However, dispersion in E. gigantea was found in all different karyotypes, unlike orthopterans, which present variation in number of sites among individuals within a species with a single karyotype (Oliveira et al. 2011; Bueno et al. 2013; Pine et al. 2017). Dispersion of histone genes is generally attributed to mechanisms that maintain highly repetitive sequences in centromeric regions, such as mobility of transposable elements, ectopic recombination, or extrachromosomal circular DNA (eccDNA), which are also proposed to explain the dispersion of other classes of repetitive DNA (Fitch et al. 1990; Raskina et al. 2004; Bione et al. 2005; Cohen et al. 2010; Nguyen et al. 2010).

The dispersion of histone genes in E. gigantea must have occurred before chromosomal diversification, considering that it is observed in all populations. No positive correlation exists between chromosome number and histone gene dispersion, since all tested karyotypes show dispersion in all chromosomes. However, as previously documented, repetitive elements can trigger chromosomal rearrangements in invertebrates (Coghlan and Wolfe 2002; Coghlan et al. 2005): they constitute hotspots for breakpoints leading to chromosomal rearrangements such as translocations (Coghlan and Wolfe 2002) and fissions (Rousselet et al. 2000), which are frequent in the chromosome evolution history of E. gigantea. Hence, the presence of a large number of histone genes in E. gigantea, as well as other repetitive sequences commonly present in the centromeric region, e.g., satellite DNA (Slamovits et al. 2001; Evans et al. 2017) and transposable elements (Raskina et al. 2008), may promote the very high frequency of rearrangements occurring throughout the chromosomal evolution of this species.

\section{Conclusions}

Several rearrangements were responsible for the formation of distinct karyotypes within and among Euchroma gigantea populations. The chromosomal variation in E. gigantea possibly started from a set with $2 n=20$, Xy, which underwent centric fissions and fusions, translocations, pericentric inversions, and Y chromosome loss. Some of these rearrangements may have been differently fixed in the three lineages exhibiting distinct geographical distribution and thus possibly contributed to the adaptation to different habitats and to the speciation process. The dispersion of histone genes that occurred before karyotypic diversification, as well as of other repetitive sequences, might have favored the high frequency of chromosomal rearrangements seen in the species.

Acknowledgements We are grateful to Dr. Fernando A. B. Silva and M.Sc. Amanda Arcanjo for providing samples from Belém, PA; to Dr. Edgar Bione for the help with specimen collection in Brasília, DF; to Dr. Sônia Casari and Dr. Carlos Campaner for providing the specimens analyzed here from the Zoology Museum at the University of São Paulo; and Dr. Cibele Sotero-Caio for the 
critical reading of the manuscript.

Funding information This study was supported by the Coordenação de Aperfeiçoamento de Pessoal de Nível Superior (Capes) (doctorate scholarships to CX and ICA), Fundação de Amparo à Ciência e Tecnologia de Pernambuco - FACEPE (APQ process number 07772.02/15 and Masters scholarship to RVSS), Fundação de Amparo à Ciência do Estado de São Paulo - FAPESP (2014/11763-8), and Conselho Nacional de Desenvolvimento Científico e Tecnológico CNPq, Brazil (PQ-2 of RCM process number 305298/2014-3).

\section{Compliance with ethical standards}

Conflict of interest The authors declare that they have no conflict of interest.

\section{References}

Bellamy C (2003) An illustrated summary of the higher classification of the superfamily Buprestoidea (Coleoptera). Folia Heyrovskiana 10:44

Bione EG, Camparoto M, Simões Z (2005) A study of the constitutive heterochromatin and nucleolus organizer regions of Isocopris inhiata and Diabroctis mimas (Coleoptera: Scarabaeidae, Scarabaeinae) using C-banding, AgNO3 staining and FISH techniques. Genet Mol Biol 28:376-381

Blackmon H, Demuth JP (2015) Coleoptera karyotype database. Coleopt Bull 69:174-175. https://doi.org/10.1649/0010-065 $\mathrm{X}-69.1 .174$

Blackwelder RE (1944) Checklist of the coleopterous insects of Mexico, Central America, The West Indies, and South America. Bull United States Natl Museum 185:189-341

Bonfield JK, Smith KF, Staden R (1995) A new DNA sequence assembly program. Nucleic Acids Res 23(24):4992-4999

Brown JD, O’Neill RJ (2010) Chromosomes, conflict, and epigenetics: chromosomal speciation revisited. Annu Rev Genomics Hum Genet 11:291-316

Bueno D, Palacios-Gimenez OM, Cabral-de-Mello DC (2013) Chromosomal mapping of repetitive DNAs in the grasshopper Abracris flavolineata reveal possible ancestry of the B chromosome and $\mathrm{H} 3$ histone spreading. PLoS One 8:e66532. https://doi.org/10.1371/journal.pone.0066532

Cabral-de-Mello DC, Oliveira SG, Ramos IC, Moura RDC (2008) Karyotype differentiation patterns in species of the subfamily Scarabaeinae (Scarabaeidae, Coleoptera). Micron 39:1243-1250

Cabral-de-Mello DC, Moura RC, Martins C (2010) Chromosomal mapping of repetitive DNAs in the beetle Dichotomius geminatus provides the first evidence for an association of 5S rRNA and histone $\mathrm{H} 3$ genes in insects, and repetitive DNA similarity between the B chromosome and A complement. Heredity (Edinb) 104:393-400

Cabral-de-Mello DC, Oliveira SG, de Moura RC, Martins C (2011) Chromosomal organization of the $18 \mathrm{~S}$ and $5 \mathrm{~S}$ rRNAs and histone H3 genes in Scarabaeinae coleopterans: insights into the evolutionary dynamics of multigene families and heterochromatin. BMC Genet 12:88

Camacho J (2005) B chromosomes. In: TR G (ed) The evolution of the genome. Elsevier, San Diego, pp 223-286

Coghlan A, Wolfe KH (2002) Fourfold faster rate of genome rearrangement in nematodes than in Drosophila. Genome Res 12:857-867

Coghlan A, Eichler EE, Oliver SG, Paterson AH, Stein L (2005) Chromosome evolution in eukaryotes: a multi-kingdom perspective. Trends Genet 21:673-682

Cohen S, Agmon N, Sobol O, Segal D (2010) Extrachromosomal circles of satellite repeats and 5S ribosomal DNA in human cells. Mob DNA 1(1):11

Colombo PC, Remis MI (1997) On the origin of B-chromosomes: neo XY systems and X-like supernumeraries in Orthoptera. Caryologia 50:151-162

Coluzzi M, Sabatini A, Torre A et al (2002) A polytene chromosome analysis of the Anopheles gambiae species complex. Science 298:1415-1418

Coutinho LM (2006) O conceito de bioma. Acta Bot Brasilica 20: 13-23

Crombach A, Hogeweg P (2007) Chromosome rearrangements and the evolution of genome structuring and adaptability. Mol Biol Evol 24:1130-1139

De Julio M, Fernander FR, Costa C et al (2010) Mechanisms of karyotype differentiation in Cassidinae sensu lato (Coleoptera , Polyphaga , Chrysomelidae) based on seven species of the Brazilian fauna and an overview of the cytogenetic data. Micron 41:26-38

Dutrillaux A, Dutrillaux B (2016) Chromosome comparison of 17 species/sub-species of African Goliathini (Coleoptera, Cetoniinae). Comp Cytogenet 10:269-282

Evans BJ, Upham NS, Golding GB et al (2017) Evolution of the largest mammalian genome. Genome Biol Evol 9:17111724

Faria R, Navarro A (2010) Chromosomal speciation revisited: rearranging theory with pieces of evidence. Trends Ecol Evol 25:660-669

Fitch DH a., Strausbaugh LD, Barrett V (1990) On the origins of tandemly repeated genes: does histone gene copy number in Drosophila reflect chromosomal location? Chromosoma 99: 118-124

Galián J, Proença SJR, Vogler AP (2007) Evolutionary dynamics of autosomal-heterosomal rearrangements in a multiple-X chromosome system of tiger beetles (Cicindelidae). BMC Evol Biol 7:158

Garcia AH (1998) Aspectos sobre a biologia de Euchroma gigantea (L., 1758) (Coleoptera - Buprestidae) em Pachira aquatica AUBLET (Bombaceae). An da Esc Agron e Veterinária 28:69-73

Goll LG, Matiello RR, Artoni RF et al (2015) High-resolution physical chromosome mapping of multigene families in Lagria villosa (Tenebrionidae): occurrence of interspersed ribosomal genes in Coleoptera. Cytogenet Genome Res 146:64-70

Gruetzner F, Ashley T, Rowell DM, Marshall Graves JA (2006) How did the platypus get its sex chromosome chain? A comparison of meiotic multiples and sex chromosomes in plants and animals. Chromosoma 115:75-88 
Houben A, Banaei-Moghaddam AM, Klemme S, Timmis JN (2014) Evolution and biology of supernumerary B chromosomes. Cell Mol Life Sci 71:467-478

Juan C, Petitpierre E (1991) Chromosome numbers and sexdetermining systems in Tenebrionidae (Coleoptera). In: Zunino M, Bellés X, Blas M (eds) Advances in Coleopterology. AEC, Barcelona, pp 167-176

Karagyan G, Kuznetsova KG (2000) Chromosome numbers and sex chromosome systems in buprestid beetles (Coleoptera, Buprestidae). Entomol Rev 80:38-49

Karagyan G, Lachowska D (2007) Karyotypes of five species of jewel-beetles and presumptive ancestral state of karyotypes of the subfamilies Polycestinae, Chrysochroinae and Buprestinae (Insecta: Coleoptera: Buprestidae). Comp Cytogenet 1:121-127

Karagyan G, Kuznetsova VG, Lachowska D (2004) New cytogenetic data on Armenian buprestids (Coleoptera, Buprestidae) with a discussion of karyotype variation within the family. Folia Biol (Kraków) 52:151-158

Karagyan G, Lachowska D, Kalashian M (2012) Karyotype analysis of four jewel-beetle species (Coleoptera, Buprestidae) detected by standard staining, C-banding, AgNOR-banding and $\mathrm{CMA}_{3}$ /DAPI staining. Comp Cytogenet 6:183-197

Kawakami T, Butlin RK, Cooper SJB (2011) Chromosomal speciation revisited: modes of diversification in Australian morabine grasshoppers (Vandiemenella, viatica species group). Insects 2:49-61

Kimura M (1980) A simple method for estimating evolutionary rate of base substitutions through comparative studies of nucleotide sequences. J Mol Evol 16:111-120

Kobayashi N, Shirai Y, Tsurusaki N, Tamura K, Aotsuka T, Katakura H (2000) Two cryptic species of the phytophagous ladybird beetle Epilachna vigintioctopunctata (Coleoptera: Coccinellidae) detected by analyses of mitochondrial DNA and karyotypes, and crossing experiments. Zool Sci 17:1159-1166

Luykx P, Syren RM (1981) Multiple sex-linked reciprocal translocations in a termite from Jamaica. Experientia 37:819-820

Martis MM, Klemme S, Banaei-Moghaddam AM, Blattner FR, Macas J, Schmutzer T, Scholz U, Gundlach H, Wicker T, Simkova H, Novak P, Neumann P, Kubalakova M, Bauer E, Haseneyer G, Fuchs J, Dolezel J, Stein N, Mayer KFX, Houben A (2012) Selfish supernumerary chromosome reveals its origin as a mosaic of host genome and organellar sequences. Proc Natl Acad Sci 109:13343-13346

Mesa A, Fontanetti CS (1984) Multiple sex-chromosomes, autosomal polymorphism and a high number of S chromosomes in Euchroma gigantea L 1735 (Coleoptera, Buprestidae). Rev Bras Genet 7:629-637

Miller MA, Pfeiffer W, Schwartz T (2010) Creating the CIPRES science gateway for inference of large phylogenetic trees. In: Gateway Computing Environments Workshop (GCE) pp 1-8

Mills PJ, Cook LG (2014) Rapid chromosomal evolution in a morphologically cryptic radiation. Mol Phylogenet Evol 77: 126-135

Moura R de C, Melo NF, Souza MJ (2008) High levels of chromosomal differentiation in Euchroma gigantea L. 1735 (Coleoptera, Buprestidae). Genet Mol Biol 31:431-437

Nagoda N, Fukuda A, Nakashima Y, Matsuo Y (2005) Molecular characterization and evolution of the repeating units of histone genes in Drosophila americana: coexistence of quartet and quintet units in a genome. Insect Mol Biol 14:713-717
Nguyen P, Sahara K, Yoshido A, Marec F (2010) Evolutionary dynamics of rDNA clusters on chromosomes of moths and butterflies (Lepidoptera). Genetica 138:343-354

Noor MA, Grams KL, Bertucci LA, Reiland J (2001) Chromosomal inversions and the reproductive isolation of species. Proc Natl Acad Sci U S A 98:12084-12088

Oliveira NL, Cabral-de-Mello DC, Rocha MF, Loreto V, Martins C, Moura RC (2011) Chromosomal mapping of rDNAs and H3 histone sequences in the grasshopper Rhammatocerus brasiliensis (Acrididae, Gomphocerinae): extensive chromosomal dispersion and co-localization of $5 \mathrm{~S} \mathrm{rDNA} / \mathrm{H} 3$ histone clusters in the A complement and $\mathrm{B}$ chromosome. Mol Cytogenet 4:24

Petitpierre E (2011) Cytogenetics, cytotaxonomy and chromosomal evolution of Chrysomelinae revisited (Coleoptera, Chrysomelidae). Zookeys 79:67-79

Pine MB, Gallo RB, da Silva CRM, Pezenti LF, de Domenico FC, Loreto V, da Rosa R (2017) Chromosome mapping in Abracris flavolineata (De geer, 1773) (Orthoptera) from the Iguaçu National Park - Foz do Iguaçu, Paraná, Brazil. Comp Cytogenet 11:203-212

Pineau P, Henry M, Suspène R et al (2005) A universal primer set for PCR amplification of nuclear histone $\mathrm{H} 4$ genes from all animal species. Mol Biol Evol 22:582-588

Pinkel D, Straume T, Gray JW (1986) Cytogenetic analysis using quantitative, high-sensitivity, fluorescence hybridization. Proc Natl Acad Sci 83:2934-2938

Raskina O, Belyayev A, Nevo E (2004) Activity of the En/Spmlike transposons in meiosis as a base for chromosome repatterning in a small, isolated, peripheral population of Aegilops speltoides Tausch. Chromosom Res 12:153-161

Raskina O, Barber JC, Nevo E, Belyayev A (2008) Repetitive DNA and chromosomal rearrangements: speciation-related events in plant genomes. Cytogenet Genome Res 120:351357

Rens W, Grützner F, O’Brien PCM et al (2004) Resolution and evolution of the duck-billed platypus karyotype with an $\mathrm{X}_{1} \mathrm{Y}_{1} \mathrm{X}_{2} \mathrm{Y}_{2} \mathrm{X}_{3} \mathrm{Y}_{3} \mathrm{X}_{4} \mathrm{Y}_{4} \mathrm{X}_{5} \mathrm{Y}_{5}$ male sex chromosome constitution. Proc Natl Acad Sci U S A 101:16257-16261

Rieseberg LH (2001) Chromosomal rearrangements and speciation in animals. Trends Ecol Evol 16:351-358

Roehrdanz R, Heilmann L, Senechal P, Sears S, Evenson P (2010) Histone and ribosomal RNA repetitive gene clusters of the boll weevil are linked in a tandem array. Insect Mol Biol 19: $463-471$

Ronquist F, Teslenko M, van der Mark P, Ayres DL, Darling A, Höhna S, Larget B, Liu L, Suchard MA, Huelsenbeck JP (2012) MrBayes 3.2: efficient Bayesian phylogenetic inference and model choice across a large model space. Syst Biol 61:539-542

Rosetti N, Vilardi JC, Remis MI (2007) Effects of B chromosomes and supernumerary segments on morphometric traits and adult fitness components in the grasshopper, Dichroplus elongatus (Acrididae). J Evol Biol 20:249-259

Rousselet J, Monti L, M a A-R et al (2000) Chromosome fission associated with growth of ribosomal DNA in Neodiprion abietis (Hymenoptera: Diprionidae). Proc Biol Sci 267: $1819-1823$

Rowell DM (1990) Fixed fusion heterozygosity in Delena cancerides Walck. (Araneae: Sparassidae): an alternative to speciation by monobrachial fusion. Genetica 80:139-157 
Rozek M, Lachowska D, Petitpierre E, Holecová M (2004) Cbands on chromosomes of 32 beetle species (Coleoptera: Elateridae, Cantharidae, Oedemeridae, Cerambycidae, Anthicidae, Chrysomelidae, Attelabidae and Curculionidae). Hereditas 140:161-170

Sambrook J, Russel DW (2001) Molecular cloning. A laboratory manual, third edit. Cold Spring Harbor, New York

Schneider MC, Rosa SP, Almeida MC, Costa C, Cella DM (2007) Strategies of karyotype differentiation in Elateridae (Coleoptera, Polyphaga). Micron 38:590-598

Sharp HE, Rowell DM (2007) Unprecedented chromosomal diversity and behaviour modify linkage patterns and speciation potential: structural heterozygosity in an Australian spider. J Evol Biol 20:2427-2439

Silvestro D, Michalak I (2011) raxmlGUI: a graphical front-end for RAxML. Org Divers Evol 12:335-337

Simon C, Frati F, Beckenbach A, Crespi B, Liu H, Flook P (1994) Evolution, weighting, and phylogenetic utility of mitochondrial gene sequence and a compilation of conserved polymerase chain reaction primers. Ann Entomol Soc Am 87:651701

Slamovits CH, Cook J a, Lessa EP, Rossi MS (2001) Recurrent amplifications and deletions of satellite DNA accompanied chromosomal diversification in south American tuco-tucos (genus Ctenomys, Rodentia: Octodontidae): a phylogenetic approach. Mol Biol Evol 18:1708-1719

Steinemann M, Steinemann S (1998) Enigma of Y chromosome degeneration: neo-Y and neo-X chromosomes of Drosophila miranda a model for sex chromosome evolution. Genetica 102(103):409-420
Sumner AT (1972) A simple technique for demonstrating centromeric heterochromatin. Exp Cell Res 75:304-306

Syren RM, Luykx P (1977) Permanent segmental interchange complex in the termite Incisitermes schwarzi. Nature 266: $167-168$

Taffarel A, Bidau CJ, Martí DA (2015) Chromosome fusion polymorphisms in the grasshopper, Dichroplus fuscus (Orthoptera: Acrididae: Melanoplinae): insights on meiotic effects. Eur J Entomol 112:11-19

Tamura K, Stecher G, Peterson D, et al (2013) MEGA6: molecular evolutionary genetics analysis version 6. 0. Mol Biol Evol 30:2725-2729

Thompson JD, Higgins DG, Gibson TJ (1994) CLUSTAL W: improving the sensitivity of progressive multiple sequence alignment through sequence weighting, position-specific gap penalties and weight matrix choice. Nucleic Acids Res 22: $4673-4680$

Vitturi R, Catalano E, Sparacio I, Colomba MS, Morello A (1996) Multiple-chromosome sex systems in the darkling beetles Blaps gigas and Blaps gibba (Coleoptera, Tenebrionidae). Genetica 97:225-233

White MJD (1973) Animal cytology and evolution. Cambridge University Press, London

Zhou Q, Zhu H, Huang Q, Xuan ZL, Zhang GJ, Zhao L, Ding Y, Roy S, Vicoso B, Ruan J, Zhang Y, Zhao RP, Mu B, Min JM, Zhang QH, Li JW, Luo YL, Liang ZH, Ye C, Li RQ, Zhang XQ, Wang J, Wang W, Bachtrog D (2012) Deciphering neosex and B chromosome evolution by the draft genome of Drosophila albomicans. BMC Genomics 13:109 